\title{
Robotic-assisted Ivor Lewis esophagectomy-end-to-end anastomosis (EEA)
}

\author{
Sean C. Wightman ${ }^{1}$, Natalie S. Lui ${ }^{2}$ \\ ${ }^{1}$ Division of Thoracic Surgery, Department of Surgery, Keck School of Medicine of the University of Southern California, Los Angeles, CA, USA; \\ ${ }^{2}$ Department of Cardiothoracic Surgery, Stanford University Hospitals and Clinics, Stanford, CA, USA \\ Contributions: (I) Conception and design: Both authors; (II) Administrative support: Both authors; (III) Provision of study materials or patients: \\ Both authors; (IV) Collection and assembly of data: Both authors; (V) Data analysis and interpretation: Both authors; (VI) Manuscript writing: Both \\ authors; (VII) Final approval of manuscript: Both authors. \\ Correspondence to: Natalie S. Lui, MD. Stanford University School of Medicine, 300 Pasteur Drive, Stanford, CA 94305, USA. \\ Email: natalielui@stanford.edu.
}

\begin{abstract}
Minimally invasive methods for treating esophageal cancer are being increasingly adopted. An Ivor Lewis esophagectomy is performed through the abdomen and then right chest, with a thoracic anastomosis. Each part of the operation can be performed using minimally invasive approacheslaparoscopic or robotic approaches in the abdomen, and video-assisted thoracoscopic surgery (VATS) or robotic approaches in the chest. The esophago-gastric anastomosis can be performed with a circular endto-end anastomosis (EEA) stapler, hand sewn, or with a linear stapler. Here, we describe a robotic technique utilizing the EEA stapler. We generally use the stapler with $28 \mathrm{~mm}$ diameter and $4.8 \mathrm{~mm}$ stapler height. The proximal esophagus is transected with robotic monopolar curved scissors. The anvil for the EEA stapler is inserted into the proximal esophagus, and two pursestrings are sewn using the robotic mega suture cut needle driver. The EEA stapler is placed through a gastrotomy at the proximal staple line of the conduit, and the spike is deployed. The stapler is tightened and deployed, then gently removed. The gastrotomy is closed with a robotic linear stapler, ensuring enough distance from the EEA staples as to not devascularize the gastric conduit. This technique requires coordination between the surgeon at the bedside and the one at the robot console.
\end{abstract}

Keywords: Robot; Ivor Lewis; esophagectomy; anastomosis

Received: 19 October 2019; Accepted: 13 January 2020; Published: 20 January 2021.

doi: 10.21037 /jovs.2020.02.01

View this article at: http://dx.doi.org/10.21037/jovs.2020.02.01

\section{Introduction}

Esophageal cancer is the 18th most prevalent cancer in the United States and five-year survival is around 20 percent (1). The majority of patients present with localized or regional disease, and surgical resection, in the form of an esophagectomy, is crucial for improved outcome (1). There are three standard techniques for an esophagectomy: transhiatal, McKeown, and Ivor-Lewis. They all use a gastric conduit to replace the esophagus. The transhiatal esophagectomy is performed through the abdomen and left neck, with a cervical anastomosis. A McKeown, or three field esophagectomy, is performed through the right chest, then the abdomen and left neck, also with a cervical anastomosis. An Ivor-Lewis esophageactomy is performed through the abdomen and then right chest, with a thoracic anastomosis. Each of these operations are increasingly performed using minimally invasive approacheslaparoscopic or robotic approaches in the abdomen, and video-assisted thoracoscopic surgery (VATS) or robotic approaches in the chest (2-4). Although technically more challenging due to the rigid chest and the esophagus lying deep in the mediastinum, minimally invasive techniques have been found to have similar oncologic outcomes 
Table 1 List of equipment used for the end-to-end anastomosis portion of an esophagectomy

Nasogastric tube - 18 French

Davinici Xi Robotic Surgical System (Intuitive Surgical,

Sunnyvale, USA)

30 degree robotic camera (Intuitive Surgical, Sunnyvale, USA)

Tip-up Fenestrated Grasper (Intuitive Surgical, Sunnyvale, USA)

Cadiere Forceps×2 (Intuitive Surgical, Sunnyvale, USA)

Monopolar Curved Scissors (Intuitive Surgical, Sunnyvale, USA)

Suction Irrigation (Stryker, Kalamazoo, USA)

Mega Suturecut Needle Driver (Intuitive Surgical, Sunnyvale, USA)

2-0 Ethibond $\times 2$ (Ethicon, Cincinnati, USA)

Large Needle Driver (Intuitive Surgical, Sunnyvale, USA)

Curved Bipolar Dissector (Intuitive Surgical, Sunnyvale, USA)

Davis and Geck laparoscopic grasper (Medtronic,

Minneapolis, USA)

$45 \mathrm{~mm}$ blue linear robotic stapler (Intuitive Surgical,

Sunnyvale, USA)

Specimen bag

Circular EEA 28 mm stapler (Medtronic, Minneapolis, USA)

$(4,5)$. Robotic esophagectomies began with the transhiatal approach-utilizing the robot for the abdominal dissection and placing the anastomosis in the neck (6).

For an Ivor-Lewis esophagectomy, the main steps in the abdominal portion are gastric dissection, ligation of the left gastric pedicle, creation of the conduit, and typically jejunostomy tube placement. The main steps in the right chest portion are the esophageal dissection including lymph nodes, delivery of the specimen and gastric conduit into the chest, and anastomosis. The purpose of this article is to discuss and review the esophageal-gastric anastomosis performed as a stapled end-to-end anastomosis (EEA). Other anastomotic techniques described in the literature include a hand sewn and partial linear stapled anastomosis $(7,8)$.

The first robotic esophagectomy was described in 2003, and the first robotic intrathoracic anastomosis was described in $2013(5,6,9)$. Utilization of the EEA stapler for constructing the anastomosis in robotic esophagectomies has been previously described. Retrospective reviews of robotic esophagectomies, utilizing the EEA stapler for an intrathoracic anastomosis, demonstrated a $0-15 \%$ leak

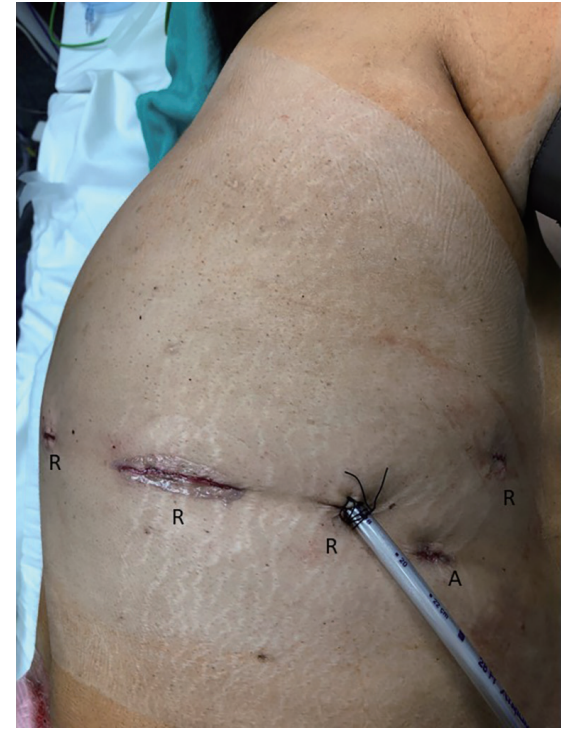

Figure 1 Visible here are the incision sites utilized for the chest portion of the esophagectomy; the robotic four (R) and one assistant (A). Most notable is the enlarged incision to accommodate the EEA stapler at the site of robotic arm two.

rate (10-15). One randomized controlled trial of sixty-one cases compared robotic-assisted esophagectomies and the utilization of stapled EEA or double-layered robotically sewn anastomoses in 2018. No significant differences in operative times were noted between the two groups which averaged 325 and 302 minutes respectively (5). Similarly, there was no significant difference found in blood loss, conversion rate, overall complication rate, or length of hospitalization (5). The study concluded that both stapled and sewn anastomoses were safe and resulted in appropriate outcomes (5).

\section{Operative technique}

The goal of this paper and associated video is to describe the technique for a robotic intrathoracic anastomosis during an Ivor Lewis esophagectomy. The equipment and instruments used are listed (Table 1). The abdominal portion including conduit creation is completed. The patient is turned to the left lateral decubitus position. Four robotic ports (three $8 \mathrm{~mm}$ and one $12 \mathrm{~mm}$ ) and one assistant port $(12 \mathrm{~mm})$ are utilized for the chest portion of a robotic IvorLewis operation (Figure 1). Our video begins with the esophageal transection (Video 1). Robot Arm 1 has the Tipup Fenestrated Grasper, Arm 2 the Cadiere Forceps, Arm 3 the 30-degree camera, and Arm 4 the Monopolar Curved 


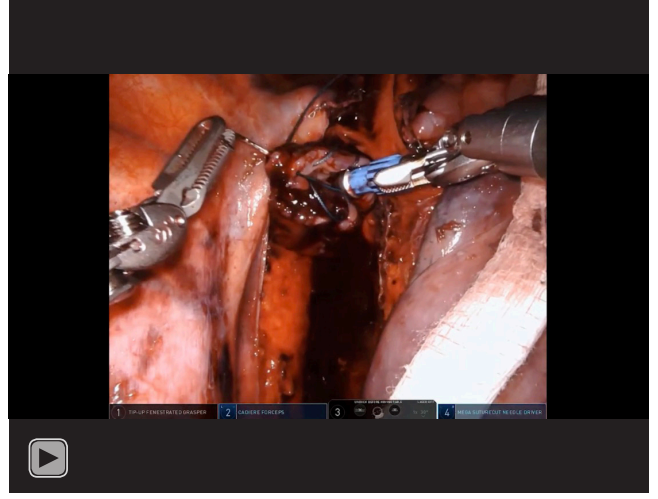

Video 1 Complete video of the end-to-end anastomosis.

Scissors. The bedside assistant is utilizing the laparoscopic suction irrigator to maintain a clean field. The esophagus is transected with multiple bites of the robotic Monopolar Curved Scissors. At 0:16 in the video, the nasogastric tube is retracted prior to complete esophageal transection with the robotic Monopolar Curved Scissors. The nasogastric tube is retracted seven centimeters proximal to the esophageal transection site so it remains within the esophagus until advanced, but does not encroach on the anastomosis.

At 0:39, the anvil for the EEA stapler is introduced into the chest. Utilizing two Cadiere Forceps through robotic Arms 2 and 4, the anvil is inserted into the proximal esophagus. At 0:53, the first pursestring begins with 2-0 Ethibond suture, cut to 15 centimeters in length, in a running fashion to secure the EEA anvil in place. This is done with a Cadiere Forceps in Arm 2 and a Mega Suturecut Needle Driver in Arm 4. The robotic Arm 1 is still unused at this time. In a simple running fashion, outside to inside, multiple bites of the distal esophagus are taken. We limit these bites to less than eight as it is difficult to tighten the pursestring if more bites are performed. At $2: 21$, the first pursestring is intracorporeally tied. At 2:55, the second pursestring begins with 2-0 Ethibond cut to 15 centimeters in length. It is performed more proximally on the esophagus than the first pursestring and involves about four bites of the esophagus. This second pursestring, done outside of the first, specifically focuses on areas of protrusion during the first pursestring or areas that may not be completely incorporated within the first.

The conduit is then brought into the chest. As haptic feedback is not available at the robotic console, the bedside assistant leads the introduction of the conduit into the chest using an atraumatic Davis and Geck instrument through the assistant port. Once delivered into the chest, the conduit is further assessed for appropriate length and the site for anastomosis is determined. Typically, this is placed just proximal to where the gastroepiploic artery terminates. Often, some gastric fat is removed from the greater curve of the stomach; seen at 4:25. This is done with the Tip-up Fenestrated Grasper in Arm 2 and the Curved Bipolar Dissector in Arm 4. This location along the greater curvature of the stomach is chosen for the anastomosis as it will ultimately permit the gastric conduit to lie anatomically with the staple line completely to the patient's right and the gastroepiploic artery on the greater curvature of the conduit to the patient's left. At 4:37, a conduit gastrotomy is created near the proximal staple line utilizing the Tipup Fenestrated Grasper in Arm 2 and the Monopolar Curved Scissors in Arm 4. This gastrotomy is where the EEA stapler is subsequently placed into the gastric conduit. Using a Davis and Geck laparoscopic retractor, the assistant aids in the opening the gastrotomy while the Monopolar Curved Scissors in Arm 4 continue the gastrotomy. Prior to introducing the EEA stapler handle, Arm 2 is undocked and its incision enlarged to accommodate the EEA stapler handle (Figure 1). At 5:28, the gastrotomy is held open by Cadiere Forceps in Arms 1 and 4, and the EEA stapler is introduced into the gastrotomy by the bedside assistant. At 5:34, the spike of the EEA stapler is deployed. Some resistance on the gastric conduit is applied with the Cadiere forceps in Arm 4. The orange line on the spike, confirming full deployment on the EEA spike, is visualized at 5:45. While the Cadiere Forceps in Arm 1 holds the gastric conduit taut over the stapler, the Cadiere Forceps in Arm 4 grasps the anvil and aligns it onto the stapler spike. Confirmation of the orange mark on the spike within the anvil is completed at 6:03. The stapler is tightened and deployed by the bedside assistant, while the Cadiere Forceps in Arm 4 ensures that all structures are out of the way, including the azygos vein stumps. The anvil is closed to minimize any incisional contamination, and the EEA stapler is removed. On the back table, the EEA stapler donuts are then examined to confirm they are intact.

The blue 45 millimeter robotic linear stapler is then introduced into the redocked Arm 2 through the enlarged incision previously used for the EEA stapler. For this portion of the operation, the Cadiere Forceps are in Arms 1 and 4, and the camera is in Arm 3. The proximal gastric conduit is gently retracted away from the mediastinum while the stapler is advanced across the gastrotomy. The stapler is closed, ensuring no other structures are trapped 
in the stapler firing. Once the stapler is closed, prior to firing, visualization of the EEA anastomosis is done to ensure the linear stapler is not too close to the EEA staple line. The stapler is fired and a second cartridge of the blue 45 millimeter robotic linear stapler is used to completely transect the proximal gastric conduit and close the gastrotomy. The stapler is then removed from Arm 2 and this robotic arm is undocked again permitting access into the chest for a specimen bag. The gastric specimen is then removed. The conduit is then assessed and the NG tube advanced with intrathoracic visualization.

\section{Tips}

* When backing up the NG tube, just withdraw about 7 centimeters, so it remains in the esophagus very proximally. This way it does not have to be nasally reinserted after the anastomosis is made and can simply be advanced.

* Aligning the spike and the anvil for a connection can be difficult. Small movements of the robotic surgeon and the assistant should be attempted.

* When firing the EEA stapler, the robotic surgeon must advance her/his left hand holding the gastric conduit simultaneously as the stapler advances and fires.

* When firing the linear stapler, ensure enough distance from the EEA staples as to not devascularize the proximal gastric conduit.

\section{Discussion}

Here we have described and demonstrated our robotic stapled end-to-end anastomosis in detail (Video 1). Utilizing the EEA stapler offers a level of reproducibility and reliability when compared to a hand sewn technique. While the EEA stapled anastomosis is not new to esophagectomies and has been described previously during a robotic esophagectomy, we emphasize its applicability and ease of integration into a robotic esophagectomy (16). While the robotic platform does not currently offer an end-to-end stapling ability, the described technique of undocking an arm for utilization of the EEA stapler is feasible and appropriate.

\section{Acknowledgments}

Funding: None.

\section{Footnote}

Provenance and Peer Review: This article was commissioned by the Guest Editor (Douglas Z Liou) for the series "Advancement in Treatment for Esophageal Diseases" published in fournal of Visualized Surgery. The article has undergone external peer review.

Conflicts of Interest: Both authors have completed the ICMJE uniform disclosure form (available at https://jovs.amegroups. com/article/view/10.21037/jovs.2020.02.01/coif). The series "Advancement in Treatment for Esophageal Diseases" was commissioned by the editorial office without any funding or sponsorship. SCW reports nonfinancial support from Intuitive Surgical, outside the submitted work. NSL reports non-financial support from Intuitive Surgical, outside the submitted work. The authors have no other conflicts of interest to declare.

Ethical Statement: The authors are accountable for all aspects of the work in ensuring that questions related to the accuracy or integrity of any part of the work are appropriately investigated and resolved. All procedures performed in this study were in accordance with the Helsinki Declaration (as revised in 2013). The manuscript is waived from patient informed consent according to the ethics committee or institutional review board.

Open Access Statement: This is an Open Access article distributed in accordance with the Creative Commons Attribution-NonCommercial-NoDerivs 4.0 International License (CC BY-NC-ND 4.0), which permits the noncommercial replication and distribution of the article with the strict proviso that no changes or edits are made and the original work is properly cited (including links to both the formal publication through the relevant DOI and the license). See: https://creativecommons.org/licenses/by-nc-nd/4.0/.

\section{References}

1. Njei B, McCarty TR, Birk JW. Trends in esophageal cancer survival in United States adults from 1973 to 2009: A SEER database analysis. J Gastroenterol Hepatol 2016;31:1141-6.

2. Broussard B, Evans J, Wei B, et al. Robotic esophagectomy. J Vis Surg 2016;2:139.

3. DeLong JC, Kelly KJ, Jacobsen GR, et al. The benefits and limitations of robotic assisted transhiatal esophagectomy 
for esophageal cancer. J Vis Surg 2016;2:156.

4. Yibulayin W, Abulizi S, Lv H, et al. Minimally invasive oesophagectomy versus open esophagectomy for resectable esophageal cancer: a meta-analysis. World J Surg Oncol 2016;14:304.

5. Zhang Y, Xiang J, Han Y, et al. Initial experience of robotassisted Ivor-Lewis esophagectomy: 61 consecutive cases from a single Chinese institution. Dis Esophagus 2018;31. doi: 10.1093/dote/doy048.

6. Horgan S, Berger RA, Elli EF, et al. Robotic-assisted minimally invasive transhiatal esophagectomy. Am Surg 2003;69:624-6.

7. Orringer MB, Marshall B, Iannettoni MD. Eliminating the cervical esophagogastric anastomotic leak with a sideto-side stapled anastomosis. J Thorac Cardiovasc Surg 2000;119:277-88.

8. Elshaer M, Gravante G, Tang CB, et al. Totally minimally invasive two-stage esophagectomy with intrathoracic handsewn anastomosis: short-term clinical and oncological outcomes. Dis Esophagus 2018;31. doi: 10.1093/dote/ dox 150 .

9. De la Fuente SG, Weber J, Hoffe SE, et al. Initial experience from a large referral center with roboticassisted Ivor Lewis esophagogastrectomy for oncologic purposes. Surg Endosc 2013;27:3339-47.

doi: 10.21037/jovs.2020.02.01

Cite this article as: Wightman SC, Lui NS. Robotic-assisted Ivor Lewis esophagectomy-end-to-end anastomosis (EEA). J Vis Surg 2021;7:5.
10. Wee JO, Bravo-Iñiguez CE, Jaklitsch MT. Early Experience of Robot-Assisted Esophagectomy With Circular End-to-End Stapled Anastomosis. Ann Thorac Surg 2016;102:253-9.

11. Okusanya OT, Sarkaria IS, Hess NR, et al. Robotic assisted minimally invasive esophagectomy (RAMIE): the University of Pittsburgh Medical Center initial experience. Ann Cardiothorac Surg 2017;6:179-85.

12. Amaral M, Pimiento J, Fontaine JP. Robotic esophagectomy: the Moffitt Cancer Center experience. Ann Cardiothorac Surg 2017;6:186-9.

13. Nora I, Shridhar R, Meredith K. Robotic-assisted Ivor Lewis esophagectomy: technique and early outcomes. Robot Surg 2017;4:93-100.

14. Wang WP, Chen LQ, Zhang HL, et al. Modified Intrathoracic Esophagogastrostomy with Minimally Invasive Robot-Assisted Ivor-Lewis Esophagectomy for Cancer. Dig Surg 2019;36:218-25.

15. Cerfolio RJ, Wei B, Hawn MT, et al. Robotic Esophagectomy for Cancer: Early Results and Lessons Learned. Semin Thorac Cardiovasc Surg 2016;28:160-9.

16. Okusanya OT, Hess NR, Luketich JD, et al. Technique of robotic assisted minimally invasive esophagectomy (RAMIE). J Vis Surg 2017;3:116. 